\title{
SNAPSHOT
}

\section{The colours of carbon}

A full spectrum of colour-based descriptions has emerged to describe the properties and distribution of organic carbon: black, brown, red, blue, green and teal. This colour-based terminology contributes to our evolving understanding of the carbon cycle by moving past traditional, broad classifications of carbon types (often as simple as inorganic vs. organic carbon), to more nuanced definitions based on carbon function, attribute, or location. For example, some of the colours (blue, green and teal) highlight the role of carbon in climate change mitigation via sequestration. Other types (black, brown and red) impact Earth's heat balance or promote cryospheric melting.

Red carbon is the newest colour in the carbon spectrum. "In its broadest context, it includes all living biological particles on snow and ice that reduce albedo to survive" describes Roman Dial, Professor at Alaska Pacific University, USA (Dial, R. J. et al. FEMS Microbiol. Ecol. 94, fiy007; 2018). Red expresses a common pigment produced by snow microorganisms, but the term also encompasses pigments spanning yellow through to purple. These colours absorb abundant green and blue wavelengths of light, melting the snow and ice, and "producing liquid water necessary for life, and freeing up nutrients (such as nitrogen and phosphorous) that are bound within ice crystals" adds Dial. Although the red carbon moniker has not yet caught on, the impact of reduced albedo from the pigments is known to increase snow melt, as seen in the Arctic (Lutz, S. et al. Nat Commun. 7, 11968; 2016), motivating increasing
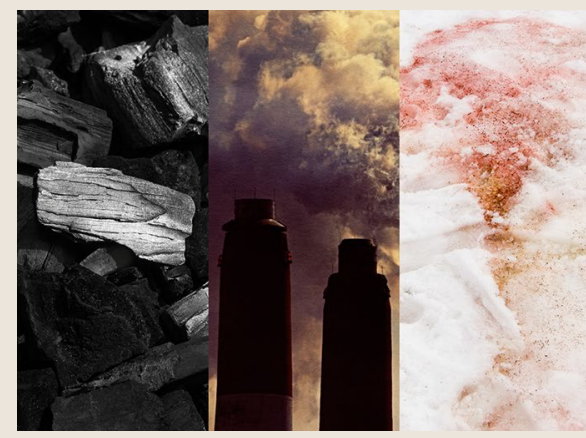

research into the role of microorganisms and the cryosphere.

Black carbon, one of the best known colours of carbon, also reduces snow and ice albedo thus increasing melting, and along with brown carbon, is produced through the incomplete combustion of organic matter. Some of the production is natural (such as during wildfires) but fossil fuel burning and industrial activities are also major sources (Bond, T. C. et al. J. Geophys. Res. Atmos. 118, 5380-5552; 2013). In comparison with black carbon, which is often described as graphitic and absorbing a wide spectrum of light, brown carbon is the visibleand UV-light-absorbing component of organic aerosols. However, both of these terms change with advancing technologies. For instance, black carbon was initially identified visually, but now Ellen Druffel, Professor at University of California Irvine, USA, notes there is a spectrum from "Char produced by partially burning biomass, and soot by the burning of fossil fuels." Similarly, a multitude of organic compounds, including some that are produced by secondary processes in the atmosphere, have been identified within the umbrella term brown carbon (Laskin, A. et al. Chem. Rev. 115, 4335-4382; 2015). What is clear for both carbon types is that in addition to reducing air quality, they absorb solar radiation at the top of the atmosphere, retaining heat and impacting climate. Yet, recent "interest in using biochar as a way to store carbon", as stated by Druffel, has led to broader research of black carbon for climate change mitigation, casting this dark carbon in a more positive light.

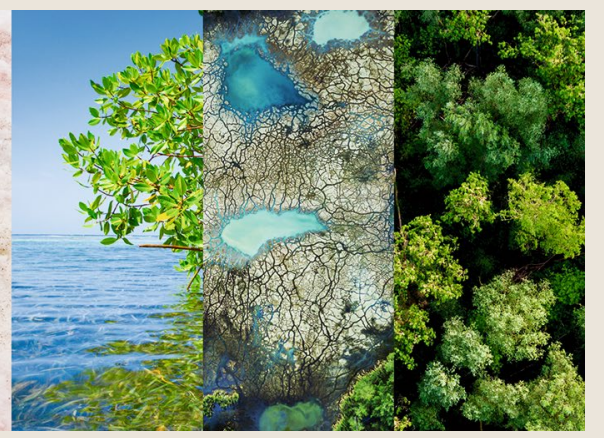

Carbon sequestration has also sparked interest in green, blue and teal carbon. These colours are united by describing the location of the carbon, rather than an inherent physical property. Green carbon reflects "the carbon sequestered by land ecosystems" states Carlos Duarte, Professor at the King Abdullah University of Science and Technology, Saudi Arabia, and incorporates carbon in soils and within biomass such as forests. Blue carbon, by contrast, describes "the carbon sequestered in the ocean", adds Duarte, "the definition of which originally focused on mangroves, salt-marshes and seagrasses, but now also includes seaweed and sediments more broadly". Lastly, teal carbon - which has only recently entered the carbon colour nomenclature relates to "the carbon stored in inland freshwater wetlands", says Siobhan Fennessy, Professor at Kenyon College, USA (Nahlik, A. M. \& Fennessy, M. S. Nat. Commun. 7, 13835; 2016). Sequestration of blue carbon, especially, has interested policymakers and environmental scientists as a solution for climate change mitigation, because as Duarte states, it "has no negative impacts, contributes to adaptation by raising the seafloor and buffering waves, provides additional benefits, such as enhanced fishery resources, and is cost-effective."

Fennessy argues, though, that "inland sites also need to be recognized for the ability they have to build carbon stocks. This is even more vital in light of the recent changes to the "WOTUS" rule (Waters of the United States), which may allow the destruction of inland wetlands that were previously protected." If destroyed, the teal carbon stored in the wetlands could act as a $\mathrm{CO} 2$ source.

Defining and effectively using terms, such as those here, can motivate the advancement and advocacy of carbon research, especially when, as Duarte states, "the demand for sound, effective and value-adding nature-based solutions for climate change mitigation is growing." These carbon colours are living definitions, though, that cross disciplinary boundaries and are expanded or refined to adapt to new knowledge, instrumentation, and policy needs. Moreover, new colours continue to emerge, as seen in the cases of red and teal. As carbon research moves forward, one wonders what the next colour of the carbon rainbow will be. 